\title{
Silencing without Convention
}

\author{
Elmar Unnsteinsson \\ Preprint. Please cite published version: \\ Pacific Philosophical Quarterly (2019) 100(2):573-598. \\ doi:10.1111/papq.12260
}

\begin{abstract}
Silencing is usually explained in terms of conventionalism about the nature of speech acts. More recently, theorists have tried to develop intentionalist theories of the phenomenon. I argue, however, that if intentionalists are to accommodate the conventionalists' main insight, namely that silencing can be so extreme as to render certain types of speech act completely unavailable to victims, they must take two assumptions on board. First, it must be possible that speakers' communicative intentions are opaque to the speakers themselves. Secondly, it needs to be assumed that structural oppression can have hidden psychological effects on its victims. Since both assumptions can be motivated independently, I argue that silencing can be fully understood without appealing to linguistic conventions.
\end{abstract}

\section{Introduction}

Talk of gender roles and stereotypes easily evokes images of theatre. One's culture provides a script of dos and don'ts for any situation, relative to the actor's perceived gender. If female, wear makeup; if male, open doors; and so on. Importantly, as feminists have argued, the script itself can be oppressive. Imagine a society, for example, in which the script clearly and unambiguously states that no female refusals of sexual advances are ever genuine, but always part of a culturally prescribed ritual, designed

*(凶) elmar.geir@gmail.com

*For helpful comments, suggestions and insightful discussion I thank Rachel McKinney, Kent Bach, Jennifer Kling, Elvira Basevich, Finnur Dellsén, Nick Hughes, Thomas Hodgson and two anonymous referees for this journal. I acknowledge the support of the Icelandic Research Fund (163132-051) and the Irish Research Council (GOIPD/2016/186) at different stages of writing this article. 
only to offset the appearance of promiscuity or similar. Arguably, in such a society, genuine female speech acts of refusing sex have become ineffective, constitutively unable to serve their intended purpose. Any effective resistance would have to resort to manipulation or physical force, rather than feeble attempts at communication.

Some philosophers have argued that a description along these lines fits many modern societies all too well and, more specifically, that production, distribution, and consumption of pornography is pivotal in creating cultural scripts where genuine refusals form no part of the roles appropriate to female actors. This is, in rough outline, the free speech argument against pornography. Pornography curtails the free speech of women-their refusals of sex are 'silenced'-and, so, there is a case to be made that it should be censored, banned, or otherwise restricted by law (West 2003). Of course, the idea is not that pornography literally makes women silent, like social norms or rules that enjoin one not to speak during a funeral or concert performance, but that the relevant utterances necessarily lack the intended force. The fundamental question is how, exactly, this notion of silencing ought to be understood.

Abstracting away from the issue of pornography, however, it soon becomes clear that the phenomenon of being silenced-if it can be properly explained-is interesting in and of itself and probably rears its head in all sorts of situations, involving all sorts of social groups. Thus, for example, structural racism might partly consist in the silencing of specific speech acts by members of a racialized group. ${ }^{1}$ More generally, the subordination of lower classes in a given society-serfs, slaves, untouchables, the working class, a colonized population, etc.-might also partly consist in their speech being silenced in the same manner.

Accordingly, this paper is concerned with developing and arguing for a theory of the property of being silenced as such, setting aside, for now, the question of which specific social groups have been or are currently silenced. Speaking very broadly, there are two types of theory to be found in the literature. One is grounded in Austinian conventionalism about the nature of speech acts and has been developed, in most detail, by Rae Langton (1993) and Jennifer Hornsby (1995). ${ }^{2}$ The other proposes that Gricean intentionalism is better equipped to reveal the nature of silencing; I refer here to the work of Ishani Maitra (2009). I argue, however, that although the latter proposal advances our understanding significantly, neither perspective is entirely correct. More precisely, while Maitra's theory correctly identifies the mechanisms of communication whose systematic disablement constitutes silencing, her account

\footnotetext{
${ }^{1}$ Sally Haslanger (2000) defines 'racialized' social groups roughly as groups whose social capital is either increased or diminished on the basis of perceived or imagined bodily features, which features are presumed to be evidence that group members have shared ancestry. See also Jennifer Saul (2006).

${ }^{2}$ Langton and Hornsby's ideas are inspired by and partly based on Catherine McKinnon's (1987, 1993) work on silencing, which I will not be focusing on here.
} 
lacks resources to capture the most worrying aspect of silencing, namely, that certain forms of intentional, expressive activity are simply unavailable to the speaker. None of the silenced speaker's actions can get to be, for example, an act of refusal.

In what follows, I argue that intentionalists need to incorporate two independently motivated assumptions into their theory if it is to fully explain the phenomenon of silencing. The first is, roughly, the idea that human minds are fragmented and can easily house two inconsistent attitudes at the same time, one perhaps being activated more readily in some contexts and the other in other contexts, resulting in a failure of full attitude-integration. Griceans usually do not extend fragmentation to speakers' communicative intentions, but I argue that this is plausible. The second assumption is that being oppressed inevitably involves significant psychological effects, even if those effects are often not conscious or introspectible. I sometimes call the resulting theory 'non-conventionalism,' as it departs from standard formulations of intentionalism. Since the conclusion is a new kind of intentionalism about meaning the argument in this paper shows how considerations of moral or political import can, on occasion, spur significant revisions of basic metaphysical assumptions.

\section{Two Theories of Silencing}

On Austin's theory, speech acts are conventional kinds; actions performed in conformity to certain specific customs or 'conventional procedures'. One of his muchcited examples is the conventional act of marrying. The act of saying 'I do' in the appropriate circumstances, by the appropriate speaker with the appropriate mental states-sincerity being the important one-partly constitutes the act of marrying. One virtue of this account, according to Austin, is that it neatly captures the variety of ways in which speech acts can be 'unhappy'. Austin was motivated, in large part, by the thought that language was for doing many things besides asserting truths or falsehoods. Purported speech acts of marrying can be unhappy, for instance, by being performed by the wrong person-your best man can't say 'He does' for you-at the wrong time in the procedure, insincerely, and so on.

Austin analyzed the 'total speech act in the total speech situation' into three kinds of acts. First, there is the locutionary act, which is the kind of speech act consisting in uttering something and meaning something by what one uttered. ${ }^{3}$ Secondly, there are illocutionary acts, the kind of speech act consisting in uttering something with a certain specific force: prediction, promise, warning, assertion, and so on. Thirdly, there is the perlocutionary act. This is, however, where the total speech act stops consisting only in conformity to conventional procedures. Perlocution is an act of bringing about

\footnotetext{
${ }^{3}$ This is a slight emendation of Austin's original account, suggested by Schiffer (1972, ch. 4).
} 
significant effects in the hearer, such as persuasion, alarm, or amusement. Such effects can, but need not, be produced by conventionalized means. Austin argues, for example, that the naturalness of 'I (hereby) argue that ...' and the unnaturalness of 'I (hereby) persuade you that ...' suggests that only the former is a conventionalized type of speech act. ${ }^{4}$

Given this threefold distinction, there will be three ways in which speech could be silenced. Locutionary silencing is the simplest, and most obviously the target of legal protections for free speech, as locution is silenced by speakers' being barred from making any meaningful utterance at all. This is, however, not a form of silencing which could plausibly ground a free speech argument against pornography. For, presumably, pornography doesn't literally prevent women from speaking. Thus, on the theory developed by Langton and Hornsby, silencing is primarily understood as illocutionary disablement of speakers. Speakers are, then, perfectly able to perform locutionary acts but-in virtue of some systematic interference-prevented from thereby performing the intended illocutionary act. ${ }^{5}$ So, supposing there is a society where all males believe female refusals of sex must be insincere, illegitimate, irrelevant, or something else, 'L\&H silencing' predicts that female speakers are unable to perform speech acts of refusing sex. They can speak about sex and, on this account, sincerely intend to refuse, but they can't pull off the illocutionary act of refusing.

But why not? Importantly, on Austin's type of conventionalism, hearer's 'uptake' is a necessary condition on the performance of illocutionary acts. Uptake consists in the hearer's understanding of the meaning and force of the utterance (Austin 1975: 116117). Take the illocutionary act of warning. Say I want to warn you that the end is nigh by telling you 'The end is nigh,' but you take me to be reciting poetry. You appreciate the locutionary act while failing to grasp the intended illocutionary force and, let's say, would have misunderstood even if the utterance had been prefixed with 'I warn you that ...' Question: did I manage to perform the speech act of warning that the end is nigh? Many will agree with Austin that I seem not to have done so. Similarly, $\mathrm{L} \& \mathrm{H}$ silencing predicts that female speakers may be unable to perform illocutionary acts of refusal, in certain structurally oppressive situations. ${ }^{6}$

It is worth stressing that $\mathrm{L} \& \mathrm{H}$ are not committed to the claim that all cases of illocutionary failure constitute silencing. Hearers can be indifferent or inattentive for

\footnotetext{
${ }^{4}$ Notice that this makes Austin's theory of the (total) speech act only partly conventional, and some theorists prefer to use 'speech act' and 'illocutionary act' as synonyms. I'll be using 'speech act' in the broader sense, including all three sub-acts, since my arguments apply equally to theories on which conformity to convention is only partly constitutive of the speech act. See Hornsby (1988) for discussion.

${ }^{5}$ On the notion of systematicity at issue, see Maitra (2004: 204).

${ }^{6}$ For discussion about structural oppression, see Frye (1983a); Young (1990); Haslanger (2004).
} 
all sorts of idiosyncratic, morally neutral reasons (McGowan 2014: 459-460). Furthermore, no systematic interference with speakers' attempts to perform perlocutionary acts can amount to silencing, either. Such interference can, surely, be oppressive and morally reprehensible but, the thought goes, it can't have anything to do with freedom of expression. Speakers cannot have the right to actually effect persuasion in hearers with their utterances. If I'm not convinced by your arguments, even after careful consideration, I haven't thereby done anything wrong or played a role in the structural oppression of you as a member of some social group or other. And there appears to be a distinction between the alleged right to express refusal-the right to be taken seriously and literally when refusing-and some imagined right to the general compliance of others. Only the former is potentially defensible as a right.

Ishani Maitra (2009: 317) points out that, if the envisaged argument against pornography crucially depends on the Austinian distinction between illocution and perlocution, there will be trouble, since this distinction is notoriously unclear. ${ }^{7}$ As we have seen, illocution necessarily involves certain consequences for the hearer, namely uptake. Perlocution would seem to require uptake too but, in addition, some more "consequential effects," such as persuasion, amusement, or fright (cf. Austin 1975: 101). As soon as one realizes, however, that illocutionary uptake may consist in the hearer being warned, ordered, or informed, the notion of 'more' consequential effects starts looking arbitrary. In what sense is it more consequential? Existing proposals to make the distinction clearer that don't invite this charge of arbitrariness tend to revise Austin's proposal in Gricean intentionalist terms (e.g., Bach \& Harnish 1979). In explaining the distinction above, I appealed to the notion of linguistic convention. ${ }^{8}$ This has long been a popular kind of explanation (Black 1963: 224, Searle 1983: 178-179, Cohen 1973). But without more elaboration it fails. The conscious mental state of having been warned by someone that the end is nigh is not distinguished from the conscious mental state of having been persuaded by someone that the end is nigh by the fact that only the latter introduces "extra-linguistic or incidental consequences of speaking” as Hornsby \& Langton (1998: 24) once put it. This looks like a distinction without a difference.

As indicated above, accounts of the illocution/perlocution distinction that avoid this problem invariably forsake Austin's conventionalism. My goal here, however, is not to show that speech acts are not conventional kinds or that conventionalists cannot account for silencing, but to develop an alternative, shifting the burden of

\footnotetext{
${ }^{7}$ Austin said that this distinction "seems likeliest to give trouble" (1975: 109). The L\&H theory has garnered an impressively long list of objections, some of which appear to depend, in different ways, on the unclarity of Austin's distinction between illocution and perlocution (Bird 2002, Wieland 2007, Jacobson 1995).

${ }^{8}$ Maitra (ibid., 317-318) argues convincingly against two other ways of marking the distinction.
} 
proof onto the conventionalist. Many would argue that the fundamental problem with $\mathrm{L} \& \mathrm{H}$ silencing is its commitment to speech acts as conventional kinds. ${ }^{9}$ But until a compelling alternative is developed such negative arguments will not carry conviction.

One promising alternative, then, is Gricean intentionalism, according to which speech acts are natural kinds specified in terms of certain specific audience-directed communicative intentions speakers have in making linguistic utterances. Fortunately, we only need to assume a very minimal type of Gricean theory, to see what silencing would look like in such a framework. We assume that speakers have at least two intentions in speaking: an informative intention and a communicative intention (cf. Sperber \& Wilson 1995). The first is simply an intention to have a particular cognitive effect on the hearer, say that they believe the end is nigh or that they form the intention to fetch a prickly pear cactus. Clearly, one can sometimes fulfill informative intentions without engaging in communication. I could intend to produce in you the belief that the end is nigh by leaving the newspaper open-displaying news of pending doomfor you to see. Here, my plan doesn't require that you recognize that this was my (informative) intention.

On the Gricean picture, communication proper only occurs with the added communicative intention. This is the speaker's intention that the hearer recognizes the speaker's informative intention. Thus, I might point to a prickly pear cactus and tell you to fetch it intending thereby (i) that you form an intention to fetch the cactus, and (ii) that you recognize my intention (i). In this case, I intend to achieve my task by performing a speech act; pointing and telling. Some Gricean theorists add a third condition, which we can call the 'directive' intention: this is the speaker's intention that the hearer's recognition of the informative intention should function, in part, as a reason for the hearer to fulfill the informative intention. More simply, if I tell you to fetch the cactus I want you to form the intention to comply partly on the basis of your recognition that I want you to comply with what I have told. Directive intentions are introduced to deal with certain intuitive counterexamples, but there is considerable debate about whether they are needed in a complete Gricean theory (García-Carpintero 2001: 102-103; Neale 1992: 547-549; Sperber \& Wilson 2015). We shall simply assume for now that they are required.

It is worth stressing, as Maitra (ibid., 327) does in her own account, that fulfillment of the informative intention is not considered necessary for successful communication. Take a simple speech act of asserting that $p$. On this view, the speaker $S$ utters

\footnotetext{
${ }^{9}$ See Wieland (2007) and Mikkola (2011) for how to spell this commitment out in more detail. But see also Maitra \& McGowan (2010) for some doubts about Wieland's conclusions. For general arguments against conventionalism see Strawson (1964); Schiffer (1972); Bach \& Harnish (1979); Harris (2016); Unnsteinsson (2017a).
} 
something to hearer $A$ with the informative intention of producing in $A$ the belief that $p$, or the belief that $A$ believes that $p \cdot{ }^{10} S$ communicates successfully, however, if and only if the additional communicative and directive intentions are fulfilled. Actually producing the belief that $p$ in the hearer is neither necessary nor sufficient. And this seems to be the correct result: to communicate an assertion that $p, S$ only needs for $A$ to recognize $S$ 's intention to produce in $A$ the belief that $p$ and, directively, that this recognition be intended by $S$ as a reason-however weak-for $A$ to actually believe that $p$.

Finally, silencing is constituted, on this type of theory, by the systematic interference of speakers' abilities to fulfill their communicative and directive intentions. The most obvious virtue of this account, in comparison to Austinian conventionalism, is the clarity of the distinction between communicative or directive disablement on one hand and informative disablement on the other (see Maitra ibid., 327-330 for discussion). The distinction resembles the illocution/perlocution distinction in that perlocutionary acts are not even potentially protected as speech acts. Similarly, the right to free speech cannot extend to a right that one's informative intentions in speaking be fulfilled, as this would involve a right to freely manipulate the contentful mental states of others; be it by producing beliefs or instilling intentions. Such an imagined right would, at least, not have anything essential to do with speech. It is arguable, however, that systematic disablement of speakers' abilities to make known through speech that they have a particular informative intention can be part of the structural oppression of a given social group, oppression which pertains exclusively to speech as such. And, thus, speakers could conceivably have a right not to suffer such disablement.

Two other virtues of the theory are, first, that speech acts turn out to be natural kinds-although the acts can be performed by conventional means-and, second, that we can now capture an intuitive difference between communicative and directive disablement. We have already described the former but the latter involves a more subtle mode of being silenced. To see clearly how directive silencing might work, imagine a society in which female speakers are never considered authoritative about the contents of their own desires. The males are considered to know better, in every case, what the females really desire. They are also thought to have authority as to their own desires. In this setting, a woman's utterance of 'I don't want dessert' may reliably signal her communicative intention to the male addressee. However, the addressee's recognition of the speaker's informative intention will not function, not even partly, as a reason for the addressee to form the belief intended by the speaker. And so,

\footnotetext{
${ }^{10}$ Grice (1969: 106-112) and others have given counterexamples to the first formulation and so the second is added as a possible fallback position.
} 
the hearer will not believe that the speaker doesn't want dessert, at least not on the basis of her utterance. Obviously, communicative silencing makes directive silencing redundant, but not vice versa. Both kinds of silencing can be caused by what Miranda Fricker (2007: 17) calls 'credibility deficits'.

Finally, I want to argue that there is a significant difference between the two theories, which has not been described in detail in the existing literature. The difference appears to count in favor of conventionalism, for intentionalism, as here understood, doesn't have the resources to explain the phenomenon in question. The difference can be approached by first distinguishing relational from singular disablement of speech acts.

\section{Relational Disablement}

$S$ 's speech act $A$ is relationally disabled in group $G$ if and only if $S$ 's performances of $A$ are not understood by members of $G$ as being performances of $A$.

\section{Singular Disablement}

$S$ 's speech act $A$ is singularly disabled if and only if no action available to $S$ constitutes a performance of $A$.

$S$ 's $A$-acts are 'silenced' if the disablement is oppressive and systematic in the requisite ways. Thus relational silencing is silencing which is essentially relative to the attitudes of members of a given linguistic community, $G$. Members of $G$ can silence $S$ simply by not being disposed to identify correctly the illocutionay force intended by $S$. Singular silencing doesn't involve essential reference to such a group as it consists in the fact that a speaker can't, by any means, perform a certain speech act.

Both theories capture relational disablement well enough. But singular disablement seems to be captured only by conventionalist accounts because, in virtue of the claim that hearer's uptake is partly constitutive of the illocutionary act, the definitions of relational and singular disablement are co-extensive. If one is relationally silenced, one is singularly silenced as well. To understand this better, note that according to conventionalism, $S$ 's performance of speech act $A$ on a given occasion is constituted by $A$ 's conforming to the conventions governing $A$-acts. Commonly, conventionalists argue that, by taking part in some rule governed activity like speaking English, speakers implicitly accept that their utterances are to have the properties assigned to them by the rules of English. So, for example, if one makes a slip of the tongue, uttering 'wasabi' where one meant to say 'Wahabi,' one's utterance is about wasabi in virtue of those rules (cf. Unnsteinsson 2017a). Further, speakers' intentions don't change the conventionally determined meaning of the sentences uttered. Similarly, if the ubiquity of pornographic depictions of women saying 'No' but meaning yes can change the conventional meaning of 'No' for women in particular contexts, then the speech 
act of refusing by uttering 'No' in such contexts becomes singularly unavailable to those women (Wieland 2007). ${ }^{11}$ Also, if the conventions state that $A$-acts can only be performed by speakers satisfying certain criteria, for example that they be vested with requisite authority, such acts can be completely off limits for speakers who lack authority. No move available to the rook, by rules of standard chess, will promote it to queen, although promotion is open to pawns.

If speech act $A$ is a natural kind constituted by the speaker uttering something with certain audience-directed intentions, performances of $A$ will be available to any speaker with the ability to form those intentions. It seems, then, that according to intentionalism speakers are never singularly silenced, for the communicative acts in question are always available to them as intentional agents. Some would, understandably, want to shrug their shoulders and say that's too bad for singular disablement. That's too quick, however. First, the most influential descriptions of silencing and similar phenomena in the literature seem aimed directly at singular silencing. This is evidence that singular silencing is what originally worried the relevant theorists. For example, Marilyn Frye writes that, in certain oppressive situations, women are completely unable to assert their anger: "Deprived of uptake, the woman's anger is left as just a burst of expression of individual feeling. As a social act, an act of communication, it just doesn't happen. It is, as Austin would have said, 'non-played'" (1983b: 89). This suggests that the phenomenon of singular silencing ought to be taken seriously. Secondly, it would surely count in favor of intentionalism if it could be made to accommodate singular silencing in some way or other. This can be done and it can be done in a way that deepens and strengthens the intentionalist or non-conventionalist theory more generally.

\section{Silencing for Fragmented Minds}

I'll propose two ways in which the intentionalist can accommodate singular silencing. The first is fully compatible with standard intentionalist accounts of communication, but not general enough to give a plausible characterization of the phenomena. The second fares better, but must also abandon some assumptions that tend to be cherished by intentionalists.

\footnotetext{
${ }^{11}$ It should be mentioned that, in creating this impression, non-pornographic depictions of sexual advances by men in popular films or popular culture more generally, are perhaps even more significant. Take the fact, for example, that, in Star Wars: The Empire Strikes Back, which has had a huge influence on popular culture, Princess Leia tries to refuse Han Solo's advances multiple times-eight times in just over a minute by one count-before he kisses her. He never receives the slightest signal of consent and the scene has been thought by many to be highly 'romantic' (McIntosh 2017).
} 
The first response is very simple. Generally speaking, Griceans agree that there must be some doxastic constraints on speakers' formation of communicative and directive intentions. One such constraint is that one cannot intend to do what one knows to be impossible. I know that it's impossible for me to fly to Paris by flapping my arms. So, arguably, I cannot flap my arms intending thereby to fly to Paris (Donnellan 1968). Similarly, I cannot intend to produce in Rachel the belief that the end is nigh by uttering 'Endirinn nálgast', if I know she doesn't understand Icelandic. In this way, some possible speech acts can be completely unavailable to speakers in certain situations. On this view, speakers can be singularly silenced by their own beliefs.

Before pointing out what's problematic about this suggestion, let's pause to mention that it accurately captures at least one important form of silencing. Some speech is silenced in virtue of the fact that social oppression is internalized by the oppressed. Consider Thomas Hill's (1973) example of the Deferential Wife. She defers to her Husband in every matter; tending not to have desires, beliefs, or intentions of her own, unless they are somehow determined by her Husband's. As Hill points out, this is compatible with her believing that men and women are equal. She just also believes that women should serve the family. Many feminists would conclude, then, that the Deferential Wife has internalized her own oppression. ${ }^{12}$

Arguably, the Wife's speech is severely restricted, as is her whole way of living. She will tend not to say particular things in particular contexts, even when doing so would seem to be in her interest. More dramatically, however, she will sometimes be unable to form communicative intentions to utter something with some particular illocutionary force. Adapting a related example from Langton \& West (1999: 186-187), suppose the Wife wants to order the Husband-or the Slave to order the Master in Langton \& West's scenario-to cook dinner. Because her oppression is internalized, the Wife also believes that her desire is improper and ought to be ignored. Suppose also that she knows, without a doubt, that the Husband will not have the slightest tendency to interpret her utterance of 'Cook dinner' as having the force of an order. He'd sooner react as if it were a joke. Now, if this is truly her epistemic state, and she still makes the utterance-out of desperation, or to experiment-it seems impossible for her to intend it fully as an order. ${ }^{13}$

\footnotetext{
${ }^{12}$ See, e.g., Sonya Charles (2010) who compares Hill's example to the real-world phenomenon of the 'Surrendered Wife,' which is some sort of program encouraging women to surrender their autonomy to their husbands for the sake of having a happy relationship. Incredibly, Charles reports, more than 100,000 women had joined the program in 2007.

${ }^{13}$ Note that this discussion is conducted entirely within the framework of all-out belief and all-out intention. This is merely a convenient idealization which doesn't affect the overall argument in this section. Possibly, the Wife has a 'partial' or 'graded' intention-in the sense of Goldstein (2016) or Holton (2008)-to perform the speech act with the force of an order. In that case, silencing will be
} 
So, we have now an intentionalist account of singular silencing. The Wife, in this case, is singularly unable to perform the speech act of uttering 'Cook dinner' with the intention, thereby, to produce in the Husband the recognition that she intends him to form an intention to cook dinner. Using this strategy to accommodate singular disablement, however, has one obvious flaw, namely that it is a necessary condition on $S$ being singularly silenced that $S$ be fully aware of the relevant features of $S$ 's oppressive situation. The Slave must know, full stop, that ordering the Master is futile. But this is surely implausible, for one can be silenced or oppressed without a slither of awareness.

According to the second response, then, intentionalists need to make two substantial assumptions to accommodate singular silencing. I believe that there are independent reasons for taking these on, but cannot argue for this conclusively here. Instead, I will spell out the two assumptions in the requisite detail, providing some motivating considerations along the way, but go on to show how they would help intentionalism in this particular debate. The first assumption is, roughly, that the contents of a speakers' mental states can be opaque to the speaker. More specifically, the content of a speakers' intention in uttering something can very well be hidden from plain view, for example in cases of self-deception. The second is that oppressive social structures tend to have very significant psychological effects on both the oppressors and the oppressed, even if these effects are not noticed consciously by those involved.

Let's start with the issue of mental transparency. One of the core commitments running through Gricean intentionalist views is that meaning-intentions-i.e., combinations of informative, communicative, and directive intentions-are metaphysically constitutive of what speakers say and mean on occasions of utterance. What is said by a speaker-as opposed to what is otherwise meant-may also be constrained to conform to the encoded linguistic meaning of the sentence uttered. But the point still holds; nothing but meaning-intentions determines what the speaker means on a given occasion, not 'context,' 'convention,' or some actual or ideal 'interpretation' (Bach 2005; Neale 2005).

Another commitment, fairly common among intentionalists, is that speakers have special epistemic access to their conscious, contentful mental states (Schiffer 1992; Neale 2016). So, for example, it is often argued that speakers simply know, in virtue of this special access, what they mean by uttering something on a given occasion. If I utter 'bank' in a sentence, I normally need no evidence to know that I mean to refer

explained in terms of the extreme effects oppression can have on the relative 'strength' of the speaker's communicative intention. Surely, this would result in a weaker notion of singular silencing, but there would still be a robust distinction between it and relational silencing. Bach \& Harnish (1979: Ch. 3) assume that communicative intentions come in various 'strengths' depending in the strength of the underlying attitude expressed and this is important to the individuation of different speech acts. 
to a financial institution rather than a river bank. My hearer, however, needs to infer what I mean from the evidence provided by the utterance and the context.

Taken together, these two commitments are very powerful, giving theorists apparent reason to reject any proposal that attributes meanings to speakers that they would never recognize as such (this is what Stephen Schiffer calls 'the meaning-intention problem'). However, there are plenty of reasons to be skeptical of transparency and, further, intentionalism can accommodate such skepticism very easily. I'll explain the latter point briefly before going into the the issue of transparency more directly. If Griceans are right, human communication fundamentally involves speakers trying to influence and manipulate the mental states of hearers, especially their beliefs and intentions. Correlatively, utterance interpretation is fundamentally a form of mindreading; the hearer's task is to infer speakers' mental states using their utterances as evidence. Thus, sincerity is in no way a necessary ingredient in human communication, according to intentionalists (see Rosenthal 1989 for the opposite view). In the most basic case of asserting that $p$, for example, speakers only need to have the intention to produce a $p$-belief in the audience, regardless of whether they in fact believe that $p$. Thus, since misrepresenting one's own mental states is often beneficial, intentionalism is compatible with the idea that speakers are often motivated to deceive their interlocutors.

Now, if we add the assumption that speakers can be self-deceived, such that the contents of their own beliefs, desires, and intentions are hidden from the plain view of conscious introspection, it seems to follow that misrepresentation can be directed at oneself and others at the very same time. That is, I could misrepresent myself as believing that $p$, in communication, both to my hearer and to myself simultaneously. If so, speakers can be insincere while consciously thinking that they are being sincere. ${ }^{14}$

But how exactly can contentful mental states be so radically opaque? Let's focus on belief for now, assuming it can be defined roughly as follows: $S$ believes that $p$ iff $S$ is (i) in mental state $M$ which represents that $p$ and (ii) $M$ is disposed to cause $S$ to act in ways that would satisfy $S$ 's desires if $p$ were true. The most popular strategies for accounting for inconsistent beliefs or belief-like attitudes, like those in play in self-deception, can be placed into three categories. The first will say that it's possible for a single agent both to believe $p$ and to believe not $p$ at the same time. While both states are, properly speaking, belief-states, they would be isolated from one another in different partitions of any single mind, making it possible that one's mind is radically opaque to oneself. The other two strategies also rely on mental partitions but only one

\footnotetext{
${ }^{14}$ Maitra (2009: 326) assumes, along with other Griceans, that speakers normally don't misrepresent their contentful mental states unless they are being intentionally insincere. As I've tried to indicate, I believe this is empirically doubtful but, also, not a necessary feature of the intentionalist picture.
} 
part of the mind gets to have genuine belief-states (as they are defined above), while the other part will only have mental states that may appear to be, in many respects, just like belief-states. I propose the following taxonomy:

A/B theories Each mind has at least two parts, each of which houses its own, fullblooded beliefs (as well as intentions, desires, etc.).

A theories Only one part of the mind houses real beliefs and if dual system psychology is right, it's the evolutionarily ancient, automatic, probably non-introspectible, and possibly 'associative' part. ${ }^{15}$

B theories Only one part of the mind houses real beliefs and if dual system psychology is right, it's the bossy, slow, usually conscious, effortful part.

So, according to $\mathrm{A} / \mathrm{B}$ theories there are both $\mathrm{A}$-beliefs and $\mathrm{B}$-beliefs and when they are inconsistent they may compete for control of behavior. A/B theories need not make any substantive commitments about the nature of the two parts, indeed, many philosophers eschew such commitments (Lewis 1982; Davidson 1982; Egan 2008; Mandelbaum 2016). Others would take on various parts of dual system psychology to distinguish the A-beliefs from the B-beliefs, saying for instance that the former will have system 1-type features (part of automatic processing, shared with other animals, etc.) and the latter system 2-type features (part of effortful and controlled processing, usually conscious, etc.) (Dennett 1987; Cohen 1995; Frankish 2004).

Theories in the other two categories must make substantive metaphysical assumptions to distinguish the two parts. A theories tend to demote so-called B-beliefs into causally inefficacious mental occurrences on display in consciousness. People will, in their ordinary, waking lives, take these occurrences to be actual beliefs, but an A theorist will insist that their real beliefs are non-introspectible system 1-type mental states, of which B-type conscious mental occurrences-images, sentences, etc.-are merely error-prone representations (e.g., Carruthers 2011). And B theories are the exact opposite, saying rather that our conscious, introspectible belief-like representations are genuine beliefs (e.g., Gendler 2008).

It is common for philosophers to assume the B-theoretic perspective, as it seems to many to conform better to common sense. However, if intentionalists want to be able to give a convincing theory of silencing, they should assume that $\mathrm{B}$ theories are

\footnotetext{
${ }^{15}$ For discussion of the problems with giving a clear-cut distinction between the two systems of dual system theory, see Evans \& Frankish (2009); Mercier \& Sperber (2017). To be clear, my argument does not depend on the assumption that some particular dual process or system theory is correct; massive modularity (Carruthers 2006) or fragmentation theory (Quilty-Dunn \& Mandelbaum forthcoming) would suffice. See also Mandelbaum (2016) for an argument against associationism about alleged system 1-type propositional attitudes.
} 
false. The best thing for intentionalists who want a theory of silencing is some kind of A theory, but it is possible to make do with an idiosyncratic A/B theory as well (see below). The fact that rejecting $\mathrm{B}$ theory makes it possible to develop a convincing intentionalist theory of silencing should be taken to count slightly against $\mathrm{B}$ theories. Fortunately, however, there are also independent reasons to avoid B theories. There is not enough space here to develop a detailed argument against B theory, but I will make two brief points to motivate the choice (see also Unnsteinsson 2017b).

First, it seems like a speaker's total belief state cannot consist in the set of Bbelieved propositions (as conceived by B-theorists), because any proposition can be a member of that set in virtue of self-deception, wishful thinking, confabulation, delusion, and the like. If B-beliefs are roughly the beliefs we're disposed to tell ourselvesvia conscious internal speech or imagery-and others that we have, they are subject to the usual systematic pressures for misrepresentation, for example to maintain a desired self-image. Our tendency for self-directed propaganda and self-deception is well documented by psychologists (Wilson 2002; Trivers 2011). B theory makes it partly or wholly constitutive of believing that $p$ that the speaker is disposed to self-represent as a $p$-believer. But if such acts of self-representation are motivationally biased, e.g. by being motivated by a desire to feel better about oneself, their contents are very unreliable indicators of the speaker's actual contentful mental states. At least, some such states will have to be determined in another way and this undermines the idea that $\mathrm{B}$ theories have the resources to account for a speaker's total doxastic or intentional state.

Secondly, as Peter Carruthers (2011, ch. 4) has argued, using different terminology, belief cannot consist in $\mathrm{B}$-attitudes to propositions because no such attitude has the right causal profile for belief. The B-belief that $p$, in a standard B-theory, is more like the state of having committed oneself to the truth of $p$. Speakers can make such a commitment to themselves in isolation, or to others in communication. The problem with identifying commitment and belief is that the former is highly relative to parameters seemingly unrelated to belief as such. The causal profile of the state of having made a commitment is not stable, as it is a direct function of other propositional attitudes or character traits. Some people are inclined to keep their commitments, others simply are not. Some people keep some of their commitments but not others, depending on to whom the commitment is made, for what reason, and so on. Unless belief is supposed to be relative in similar ways, which is doubtful, the identification appears unmotivated. Assuming, then, that we want to keep a definition of belief along the lines given above, $\mathrm{B}$ theories seem badly positioned to explain how a given doxastic state is determined.

For simplicity I will develop a non-conventionalist theory of silencing on the basis of an A-theoretic perspective. As indicated, A/B theory could be adopted as well, but 
only with certain complicating factors. Specifically, even if both A-attitudes and Battitudes would count as genuine propositional attitudes, in cases of conflict only the one that happens to be nonconscious could be assumed to determine what the speaker actually means by uttering something on a given occasion (I give an example of this in the next section). Thus, this distinction only applies to the determination of what speakers say or mean by their words and not, for example, to beliefs as such.

Assuming the A-theoretic perspective, then, the common sense intuition that people always have transparent access to their own contentful mental states turns out to be an illusion. But it's an illusion with a ready explanation. When we commit to the truth of some proposition $p$, we certainly think of ourselves as simply describing a belief that we know we have, but that's not what we are really doing. Our actual belief could be hidden from us. The point is not a skeptical one, however, so it might turn out that we're right most of the time. And, even when we are wrong, the very act of commitment to $p$ being true may bring about every appearance that one really does believe that $p$, especially if the thinker in question is strongly inclined to follow through on commitments. Furthermore, the undeniable appearance that one believes that $p$, because one is so committed, may in due course bring it about that one actually A-believes that $p$. And this means that speakers can gain, diachronically, first-person authority over their basic propositional attitudes, in virtue of self-fulfilling acts of commitment.

Now, if beliefs and desires can have such a dual structure, it is plausible to assume that mental states of intending can too. Intentions can be future-directed, in that they are states of intending to perform an action at a later time. But the mental state of intention can also characterize an action at the time of its performance; one has the intention in action; it is present-directed. This latter sense is what intentionalists have in mind when they define speech acts in terms of the meaning-intentions with which they are performed. Thus the duality to be described only concerns the latter. ${ }^{16}$ With all of this in place, we can finally conceptualize the possibility of speakers who consciously self-represent some action, already under way, as being performed with a particular meaning-intention while, in reality, there is a different meaning-intention at work, or no meaning-intention at all.

To simplify, using the taxonomy introduced above, we can say that the speaker's Bintention misrepresents their underlying A-intention, although both can be operative in explaining the relevant piece of behavior. On this view there will be a clear sense in which speakers are trying to execute their B-intention, even if there happens to be a conflicting A-intention. They may have deceived themselves into thinking that

\footnotetext{
${ }^{16}$ Frankish (2004: 209-213) expresses doubts that the former can have the dual structure required by his particular type of $\mathrm{A} / \mathrm{B}$ theory.
} 
the B-intention can be fulfilled, while knowing, in their heart of hearts, that that's not true. So, for example, the Slave might indeed try to perform the speech act of ordering the Master to cook dinner by uttering 'Cook dinner,' while knowing full well that this is impossible. ${ }^{17}$ The Slave's conscious B-intention fails to accurately represent any underlying A-intention. And, so, the act itself is properly called delusional and the theory predicts that the speaker is constitutively unable to intend the utterance as an order. But this disablement can be accompanied by self-deceptive acts of representing oneself to oneself as having the impossible intention in acting. And so, finally, we have the possibility of singular silencing on an intentionalist theory.

\section{The Psychology of Being Oppressed}

This raises a very important set of questions, however. How could oppression, or any social structure for that matter, so influence one's contentful mental states-which are possibly non-introspectible-that a certain class of intentional action thereby becomes impossible for one to perform? More pressingly, how could one be unable to perform an action with a particular intention, when one represents oneself to oneself, in consciousness, as doing exactly that during its undertaking?

First of all, we should question the assumption, which has been made here, that oppression is possible without a slither of awareness on the part of the oppressed (or the oppressor). As we saw, communicative disablement counts as silencing only if it's grounded in a socially distributed pattern of inequality and oppression targeting a particular social group. And structural oppression essentially involves a suite of psychological effects on its victims. Most directly, oppression is partly perpetuated by victims receiving social signals of inferiority, subservience, and incompetence. The cognitive and behavioral effects of stereotypical thinking provides the starkest and most researched confirmation of this. In societies where there is general economic, political, and social inequality favoring males over females, people tend to form stereotypes of females as inherently inferior. And, since the stereotype is formed in reaction to publicly available information - the representation of women in media, their general absence in presentations of history and politics, etc.-it is likely to be shared by everyone, often without reflective awareness. Thus, one is predicted to believe in the stereotype even if it is harmful and one takes oneself to belong to the target group. As Sandra Lee Bartky asks, considering the possibility that she herself believes harmful stereotypes about women: "why should I not believe what everyone else believes?" (1990: 24). Further, if some studies of stereotype threat in social psychology are to be

\footnotetext{
${ }^{17}$ Thus I disagree with my former self, who implied that speakers must be consciously aware of their belief that the action is impossible, for it to constrain their intentions (Unnsteinsson 2018: 10).
} 
trusted, priming negative stereotypes has detrimental effects on subjects' performance in various cognitive tasks (e.g., priming the stereotype that girls are bad at math is believed by some researchers to negatively effect the performance of girls in math tests). ${ }^{18}$

It is undeniable that individuals receive signals, from themselves and others, to the effect that they belong to a stereotypical group and that this shapes their conception of the actions and ways of living available to them. In Western societies, females are expected to (want to) be primary care-takers of children and elderly relatives. Having no desire or ability to perform such tasks often provokes unreflective criticism, making it difficult for one not to be judged, morally or otherwise, in light of this expectation or social norm. Apparently, the stereotype need not be endorsed by anyone in the group in question for it to play a potentially harmful role in influencing one's thoughts and actions in a particular context. As Elizabeth Anderson (2010: 53-55) argues, the mere fact that some stereotype has public standing can constitute an 'expressive harm'. Public standing can involve what Anderson calls 'default status,' understood in terms of people's sensitivity to the fact that the stereotype is normally taken for granted in social interactions in their society. Thus, in meeting a complete stranger in an unstructured setting, a woman may be motivated by a belief that she needs to explain why she doesn't desire to have or take care of children, in virtue of a stereotype that no one in the context consciously endorses. Everyone may very well be disposed to disavow the stereotype. But people's implicit or explicit beliefs are usually not known to all in advance. So, even mere default status of an oppressive stereotype can have significant psychological effects and influence one's judgment about what one can do or say. When the stereotype is highly entrenched the upshot can, apparently, be the singular silencing of a speaker. Just consider the case of a young woman trying to communicate her actual and honestly held desire not to bear children in her lifetime. In many normal contexts she will not be believed-'Every woman wants to have children eventually,' etc.-even after trying to convey her attitude repeatedly and emphatically. Moreover, often she will be distinctly aware of this communicative problem beforehand, realizing that what she is about to express will probably not be accepted as the plain truth. This knowledge, even if the speaker is not fully conscious of it, can clearly have the effect of silencing one's speech. ${ }^{19}$

But what exactly is the nature and extent of the psychological effect? This has been discussed in detail by social scientists and psychologists and any answer will

\footnotetext{
${ }^{18}$ As is well known, however, many of the relevant studies are now thought to be unreplicable, leading to the so-called 'replication crisis' in social psychology (Open Science Collaboration 2015). But the argument here only requires the weaker and less controversial assumption that stereotypes have effects on thought and behavior.

${ }^{19}$ Thanks to Jennifer Kling for pointing out how good this example is for the theory on offer here.
} 
be controversial. But even theorists who argue strongly against the idea that the oppressive ideology of the dominant can seep into the minds of those who suffer it most, determining their actual beliefs and attitudes, don't argue that it is impossible. James Scott (1990), to take a prominent example, argues that oppression gives rise to various everyday strategies of resistance, falling short of open rebellion. ${ }^{20} \mathrm{~A}$ telling example is that of feigning ignorance or incompetence to thwart the master's wishes. This can benefit a group or individual in the short-term, making it possible to refuse to comply with orders without publicly defying authority, which can be dangerous. "In playing dumb," Scott writes, "subordinates make creative use of the stereotypes intended to stigmatize them" (p. 133). An important long-term disadvantage, however, is that this tends to confirm the oppressor's view of subordinates as inferior (p. 33). But it doesn't follow, on his account, that the powerless automatically accept their own inferiority as natural or inevitable. However, in making this point, Scott excludes social groups whose members tend to perceive their actions as freely chosen, and for good reason (p. 109-110). Slaves, for example, will tend to perceive their own coerced actions as coerced; they wouldn't perform slave labor were it not for their awareness of constant surveillance, threat of severe punishment, and so on. ${ }^{21}$

Cases of high perceived choice appear to be very different, however. Within the experimental paradigm of induced compliance, individuals are manipulated into performing actions that would strongly imply their acceptance of beliefs or attitudes they don't in fact endorse. Using this paradigm, social psychologists have provided evidence that merely thinking of one's action as chosen substantially increases the action's potential to effect change in one's actual attitudes, pushing one closer to attitudes one would have disavowed before the experiment. In one of the most cited studies, it was concluded that making people write counterattitudinal essays made the writer's attitude more favorable to the point of view of the essay under conditions of perceived choice. Intuitively, the thought can be understood as: I argued that $p$, and I wouldn't have chosen to do so unless I believed that $p$, so I must believe that $p$ (Linder, Cooper, \& Jones 1967). Other explanations come more easily to mind when one is, say, well compensated or threatened: I only did it because of the money, etc. Work within reactance theory tends to the same conclusion, namely that threats to one's freedom in acting diminish the potential for a corresponding attitudinal change while high perception of choice increases it (Brehm \& Brehm 1981). Perceived threats

\footnotetext{
${ }^{20}$ Thanks to Rachel McKinney for alerting me to the relevance of Scott's work here and for very helpful conversations about the issues involved.

${ }^{21}$ For the dominant ideology to infiltrate the minds of slaves, Scott suggests, they would have to be completely isolated from one another-eliminating the possibility of conspiracy against dominationor each would have to believe that he or she could become master one day (p. 82-83). See Lukes (2005: 124-134) for criticism of Scott's theory on this point.
} 
to freedom may indeed have a boomerang effect, making it more likely that people adopt the opposite attitude to the one they are told to accept (e.g., Dean, Austin, \& Watts 1971). ${ }^{22}$

If this is right, men's subordination of women is much more likely to result in some degree of victims' internalization of dominant ideology than the master's oppression of his slave, even according to those generally skeptical of such 'hegemonic incorporation.' Women are, historically and in patriarchies of the present, much more likely to perceive their individual actions and their broader social situation as freely chosen and, thereby, more likely to change or sustain their attitudes so as to maximize attitude-action consistency. And, since many of those actions will, because of male domination, appear to imply the endorsement of patriarchal ideology, women are predicted to form beliefs and attitudes derived from or consistent with that ideology. Of course, this is not to suggest that revolutionary consciousness is impossible for women-we have the history of feminism to disprove that-just that it is more difficult in situations of perceived choice. And, surely, choice is often not perceived at all. Generally speaking, even total internalization does not imply the impossibility of attitude change, only that it may be more difficult. A similar point applies, it would seem, to some modern societies characterized by structural racism, where the structure is largely opaque to both the oppressor and the oppressed.

According to the non-conventionalist theory, then, singular silencing can only occur in very specific circumstances and, perhaps, only in a narrow range of cases. In particular, it requires some degree of internalization, even if merely at the level of A-attitudes, of dominant patriarchal ideology. Minimally, this involves being guided in one's thought and action, by stereotypes stigmatizing one's own social group. So, for example, a speaker can be singularly silenced, on a given occasion of utterance, in virtue of merely A-believing the relevant self-stigmatizing stereotype or, possibly, that the stereotype has default status in her society. These A-attitudes are in principle compatible with any conscious or reflective B-attitude purporting to represent or express the former. An oppressed person may be inclined to openly disavow any endorsement of the stereotypes, but this may be the result of self-deception, wishful thinking, feigned ignorance or the like. That is to say, A-level internalization is compatible with all manner of variation in one's reflective attitudes (or B-attitudes more generally). Importantly, however, as many have pointed out in debates about implicit bias, one can become conscious that one has the bias, without thereby being able to eradicate it or know how to do anything about it. Even if it is controversial,

\footnotetext{
${ }^{22}$ Attribution theory makes a similar assumption, namely that chosen action requires internal explanation and, so, if the action is counterattitudinal its performance may cause one to self-attribute the relevant internal state, rather than cite external causes (e.g., Bem 1972; Bradley 1978).
} 
however, whether individual bias can be changed by mere conscious effort, it is not controversial that mere awareness gives impetus to collective political action, which can obviously change social structures to the better. Finally, the non-conventionalist is free to posit that relational silencing is more prevalent than singular silencing and thus explain why silencing in general appears to be such a common phenomenon.

I conclude, then, that there is viable non-conventionalist theory of singular silencing. It just turns out that such a strong form of silencing is much harder to achieve than the conventionalist picture assumed; we need to theorize about the speaker's implicit attitudes. This is not a mark against non-conventionalism, however, for, as we have already seen, there are plenty of other problems ailing the conventionalist perspective. One reason for this, I suggest, is the prediction that singular silencing is easy to come by; all one needs is a linguistic practice governed by conventions according which, e.g., women who say 'No' to sex really mean Yes or Maybe, try again (Wieland 2007; Mikkola 2011). As we have seen, it's plausible to think that something much more extreme is needed, and this is exactly what the intentionalist or non-conventionalist perspective demands. Furthermore, non-conventionalism helps to explain why the Slave would do something so obviously futile as trying to order the Master to do something. She would only do so if she is disposed, for some reason, to misrepresent her communicative options to herself. In principle, this kind of explanation is available to the conventionalists as well, but they carry the additional burden of explaining why someone would perform a communicative act which they know is not even part of "the master-slave language game" (Langton \& West 1999: 187).

In closing, then, let's look at how this theory would describe realistic cases of communicative disablement. I'll do this by discussing two examples used by feminist philosophers. The first is one which Langton (1993: 33-34) borrows and adapts from Austin. Suppose $S$ says to $H$,

\section{(1) Shoot her}

referring to a woman close by. Langton uses the case as one where $S$ intended the utterance of (1) as mere advice to $H$ but, for some reason, $H$ takes it as an order. Since force, on the Austinian theory, is partly defined in terms of uptake, Langton argues that $S$ in fact performs a speech act with the illocutionary force of an order. This is an 'objective' property of the speech act. And so, there is a sense in which $S$ is communicatively disabled-this seems not to rise to the name of 'silencing' howeverin that (1) doesn't get to count as mere advice and must have the force of an order, whatever the intention of the speaker.

The non-conventionalist theory on offer here would describe things differently. There are two possibilities. First, $S$ really did intend-both in the A-sense and B-sense(1) as mere advice and had no disposition at all to expect $H$ would take it as an order. 
If $H$ still takes (1) as an order $S$ could only be relationally disabled. It just so happens that $S$ 's group doesn't understand $S$ 's performance of the speech act of giving advice as the speech act of giving advice. Secondly, however, if $S$ happens to be aware that $H$ might take (1) as an order, for example because $H$ is $S$ 's subordinate, intending (1) as a piece of advice might very well be a form of self-deception on $S$ 's part. $S$ merely consciously entertains a self-representation as of intending to give advice by uttering (1). In other words, $S$ B-intends to be giving advice-and this may be motivated by $S$ wishfully thinking that then $S$ is not responsible for $H$ 's subsequent action-but the underlying A-intention is one of issuing an order (since $S$ knows it will probably be taken as such). Non-conventionalism assumes, then, that $S$ 's A-attitudes make the fulfillment of $S$ 's self-deceptive B-intention impossible and, thereby, $S$ is singularly disabled in intentionally performing the speech act of giving advice by uttering (1) on this occasion.

It's important to notice that since illocutionary force can be radically underdetermined by the linguistic meaning of the uttered sentence, speakers automatically acquire the power of plausible deniability. One can easily get away with denying, after the fact, that an utterance was intended as an order when, actually, it was-knowingly or not-intended as an order. It should be uncontroversial that speakers' beliefs about plausible deniability feed directly into their utterance design, and not only for politicians. But, just as deniability can be used as a tool to deceive others, it can motivate a form of self-deception or, at least, a mismatch between B-attitudes and A-attitudes. If speakers can plausibly lie to others that an utterance was an order, they can also lie about the same thing to themselves.

Finally, before leaving this example, note how it could be described in the framework of an A/B theory. The speaker A-intends (1) as an order but B-intends it as mere advice, and both states count as bona fide intentions of the speaker, at the same single moment, in making the utterance. But this doesn't seem coherent unless one of the two intentions is nonconscious. But which intention would then determine the conditions of communicative success, the conscious one or the nonconscious one? I think both answers are possible here but, intuitively, I favor the view that the nonconscious intention is determinative. That is to say, the hearer understands what the speaker means if, and only if, he or she takes the speaker to be making an order. Arguing for this claim is a story for another occasion. I note this here only to establish the point that the non-conventionalist theory of silencing is compatible with an idiosyncratic version of $\mathrm{A} / \mathrm{B}$ theory as well as a simpler $\mathrm{A}$ theory.

We started with the example of refusing sex and now we can see three ways, or stages, in which such a speech act might become silenced on a non-conventionalist theory. First, the speech may be merely relationally silenced in that it cannot, as a matter of fact, be understood by the audience as the kind of speech act it actually is. 
So, for example, if there is a type of context where male hearers will systematically take female utterances of 'No' to mean yes, the act of refusal, in that context, will fail to have the effect of making the speaker's communicative intention known to the hearer. Possibly, silencing of this kind occurs even in cases where the oppressed has no awareness at all, implicitly or explicitly, that she is the victim of oppression. In such cases, however, it is arguable that the speaker is merely epistemically 'lucky' in that she genuinely forms the belief that a particular speech act is available to her, while in fact it is not. Thus, her oppressive situation makes it the case that some her beliefs about what she can and cannot do happen to be false and this is, on some views at least, a type of (broad) psychological effect. So, even if this kind of ignorance makes the mere performance of a speech act available to one, one is not necessarily free from the silencing effects of oppression.

Secondly, the speech act may be singularly silenced in virtue of the speaker's implicit or explicit belief that it cannot have the intended or hoped-for effect on the audience. Clearly, then, singular silencing can occur in many different ways, some of which are both terrifying and chilling. The speaker may of course still try to perform the speech act of refusal, and this would usually be better described as desperation than self-deception. As we have seen, the stereotypes of patriarchal societies can have strong effects on women's psychology, even if they fall short of total internalization. For instance, it can be mutually known that certain actions-apparent refusal being one-are commonly taken to be ambiguous. So, the victim may think to herself: I gave him an inviting look when I refused, so I myself am partly to be blamed, I wasn't forthright enough. After thinking these thoughts, it can be less likely that an utterance of 'No' will be accompanied by the same conviction or expectation of success, and lack of seriousness is signaled all too readily by body language and prosody. Obviously, however, all of this depends on the particular case. But, as is well known, 'freezing up' is a very common response to cases of sexual assault and part of the explanation may be that the victim becomes aware that they are powerless; nothing they can say or do will change the perpetrator's mind.

The third and last stage of being silenced is the one of having completely internalized the entire world of norms that define one's own oppression. This is the extreme case of someone who believes in their own inferiority and the inevitability or naturalness of their subordination. Assuming that this is possible, which some would doubt, victims would be silenced in something approximating the literal sense. They would not refuse their master of what is his. But they wouldn't do so because they wouldn't, in any way, form the requisite desires and intentions. If this is hard to imagine for some, particularly in the case of refusing offers of sex, we do well to remind ourselves that, until fairly recently, legal and public norms in many Western societies excluded the very possibility of 'marital rape'. In a case judged in the US in 1977 it was argued 
by the court that the husband is "legally incapable of raping his wife" because of the presumed consent-or, should we say, 'forced sexual labor'?-involved in the very act of marriage (Schiappa 2003: 56). One can imagine, then, that such norms became internalized by a whole population, even those so violently treated by their operation. However, as Scott (1990) argues, one should not simply assume that the attitudes of subordinates can be surmised on the basis of legal codifications or other official texts authored by those in power. If women have channels to conspire collectively against men-even if only through rumors, evasions, feigned ignorance, etc.-they will have the means to sustain attitudes and beliefs which accurately represent their situation as unjust.

\section{Conclusion}

I have argued that the intentionlist theory of silencing is, generally speaking, more plausible than the more popular conventionalist theory. The intentionalist theory, however, seemed not well equipped to explain a major conventionalist insight, namely the possibility of singular silencing. Responding to this problem, I proposed some significant, but independently motivated, revisions to intentionalism. Roughly, if we assume that speakers are fairly easily self-deceived or deluded about their own propositional attitudes, structural oppression can affect their mental states in such a way that they are singularly silenced by their own attitudes. This can occur, in the most extreme case, when the speaker consciously has the thought that they can perform some speech act, while in fact knowing full well that it is impossible. So, even if Austin was wrong to argue that the speech act of warning cannot be performed without audience uptake, it is still the case that a speaker who knows full well that a given utterance won't be taken as a warning cannot rationally intend the utterance as a warning. Of course, in terms of the distinction between A- and B-attitudes, the speaker might B-intend the utterance as a warning. Here I have only been able to argue very briefly for the view that B-states are not determinative of what the speaker actually means in cases of conflict, but I plan to address this issue in future work.

Even so, the main point of the paper is to show that it is possible-contrary to what seems to be a common assumption-to account for singular silencing without appealing to linguistic conventions. And the non-conventionalist view developed here also seems to help explain why a silenced speaker would speak at all-but this remains puzzling on the conventionalist theories I am aware of. In conclusion, we have seen that there is reason to think that the nature of silencing cannot be captured without theorizing about its psychological effects, although this leads into fairly controversial territory, namely the possible attribution of self-deception to members of oppressed 
social groups. But the non-conventionalist perspective demands that this possibility be explored.

\section{Bibliography}

Anderson, E., 2010. The imperative of integration. Princeton University Press.

Austin, J. L., 1975. How to Do Things with Words. Clarendon Press.

Bach, K., 2005. “Context ex machina.” Z. G. Szabó (ed.), Semantics versus pragmatics, Clarendon, pp. 15-44.

Bach, K. \& Harnish, R., 1979. Linguistic communication and speech acts. MIT Press.

Bartky, S. L., 1990. Femininity and Domination: Studies in the Phenomenology of Oppression. Routledge.

Bem, D. J., 1972. "Self-perception theory." Advances in experimental social psychology, 6:1-62.

Bird, A., 2002. "Illocutionary Silencing.” Pacific Philosophical Quarterly, 83(1):1-15.

Black, M., 1963. “Austin on Performatives.” Philosophy, 38(145):217-226.

Bradley, G. W., 1978. "Self-serving biases in the attribution process: A reexamination of the fact or fiction question." Journal of personality and social psychology, 36(1):56.

Brehm, S. S. \& Brehm, J. W., 1981. Psychological reactance: A theory of freedom and control. Academic Press.

Carruthers, P., 2006. The architecture of the mind: Massive modularity and the flexibility of thought. Clarendon Press.

---, 2011. The Opacity of Mind: An Integrative Theory of Self-Knowledge. OUP Oxford.

Charles, S., 2010. "How Should Feminist Autonomy Theorists Respond to the Problem of Internalized Oppression?" Social Theory and Practice, 36(3):409-428.

Cohen, L. J., 1995. Essay on Belief and Acceptance. Oxford University Press UK.

Cohen, T., 1973. "Illocutions and Perlocutions." Foundations of Language, 9(4):492-503.

Davidson, D., 1982. "Paradoxes of rationality." R. Wollehim \& J. Hopkins (eds.), Philosophical Essays on Freud, CUP, pp. 289-305.

Dean, R. B., Austin, J. A., \& Watts, W. A., 1971. "Forewarning effects in persuasion: Field and classroom experiments." Journal of Personality and Social Psychology, 18(2):210.

Dennett, D., 1987. The intentional stance. MIT Press.

Donnellan, K., 1968. "Putting Humpty Dumpty together again." The Philosophical Review, 77(2):203-215. Repr. in Donnellan (2012), pp. 31-48.

,--- 2012 . Essays on reference, language, and mind. OUP.

Egan, A., 2008. "Seeing and Believing: Perception, Belief Formation and the Divided Mind.” Philosophical Studies, 140(1):47-63. 
Evans, J. \& Frankish, K., 2009. In Two Minds: Dual Processes and Beyond. Oxford University Press.

Frankish, K., 2004. Mind and Supermind. Cambridge University Press.

Fricker, M., 2007. Epistemic Injustice: Power and the Ethics of Knowing. Oxford University Press.

Frye, M., 1983a. "Oppression.” The Politics of Reality: Essays in Feminist Theory, Crossing Press, pp. 1-16.

-- , 1983b. The Politics of Reality: Essays in Feminist Theory. The Crossing Press.

García-Carpintero, M., 2001. "Gricean rational reconstructions and the semantics/pragmatics distinction." Synthese, 128(1-2):93-131.

Gendler, T. S., 2008. "Alief and belief." The fournal of philosophy, 105(10):634-663.

Goldstein, S., 2016. “A Preface Paradox for Intention.” Philosophers' Imprint, 16(14).

Grice, P., 1969. “Utterer's meaning and intention.” The Philosophical Review, 78(2):147177. Repr. in Grice (1989), pp. 86-116.

,--- 1989 . Studies in the way of words. HUP.

Harris, D. W., 2016. "Intentionalism versus The New Conventionalism." Croatian Journal of Philosophy, 16(4):173-201.

Haslanger, S., 2000. "Gender and Race: (What) Are They? (What) Do We Want Them to Be?” Noûs, 34(1):31-55. Repr. in Haslanger (2012), pp. 221-247.

-- , 2004. "Oppressions: Racial and Other." M. Levine \& T. Pataki (eds.), Racism, Philosophy and Mind, Cornell University Press, pp. 97-123.

-- , 2012. Resisting Reality: Social Construction and Social Critique. OUP.

Hill, T. E., 1973. "Servility and Self-Respect." The Monist, 57(1):87-104. Repr. in Hill (1991), pp. 4-19.

-- , 1991. Autonomy and Self-Respect. Cambridge University Press.

Holton, R., 2008. "Partial Belief, Partial Intention." Mind, 117(465):27-58.

Hornsby, J., 1988. “Things Done With Words.” J. Dancy, J. M. E. Moravcsik, \& C. C. W. Taylor (eds.), Human Agency: Language, Duty, and Value, Stanford University Press, pp. 27-46.

---, 1995. "Disempowered Speech.” Philosophical Topics, 23(2):127-147.

Hornsby, J. \& Langton, R., 1998. "Free Speech and Illocution.” Legal Theory, 4(1):21-37. Revised edition in Langton (2009), pp. 75-87.

Jacobson, D., 1995. "Freedom of Speech Acts? A Response to Langton." Philosophy and Public Affairs, 24(1):64-78.

Langton, R., 1993. "Speech Acts and Unspeakable Acts." Philosophy and Public Affairs, 22(4):293-330. Repr. in Langton (2009), pp. 25-63.

---, 2009. Sexual Solipsism: Philosophical Essays on Pornography and Objectification. OUP Oxford.

Langton, R. \& West, C., 1999. "Scorekeeping in a Pornographic Language Game." 
Australasian fournal of Philosophy, 77(3):303-319. Repr. in Langton (2009), pp. 173195.

Lewis, D., 1982. "Logic for Equivocators.” Nô̂s, 16(3):431-441.

Linder, D. E., Cooper, J., \& Jones, E. E., 1967. "Decision freedom as a determinant of the role of incentive magnitude in attitude change." Journal of Personality and Social Psychology, 6(3):245.

Lukes, S., 2005. Power: A radical view. Palgrave Macmillan, 2 edn.

Maitra, I., 2004. "Silence and Responsibility." Philosophical Perspectives, 18(1):189-208.

---, 2009. "Silencing Speech." Canadian Journal of Philosophy, 39(2):309-338.

Maitra, I. \& McGowan, M. K., 2010. "On Silencing, Rape, and Responsibility." Australasian fournal of Philosophy, 88(1):167-172.

Mandelbaum, E., 2016. "Attitude, Inference, Association: On the Propositional Structure of Implicit Bias." Noûs, 50(3):629-658.

McGowan, M. K., 2014. "Sincerity Silencing." Hypatia, 29(2):458-473.

McIntosh, J., 2017. "Predatory Romance in Harrison Ford Movies." URL ht tps : / / www . youtube. com/watch? V=wWoP8VpbpYI.

McKinnon, C., 1987. Feminism Unmodified. Harvard University Press.

---, 1993. Only Words. Harvard University Press.

Mercier, H. \& Sperber, D., 2017. The enigma of reason. Harvard University Press.

Mikkola, M., 2011. "Illocution, Silencing and the Act of Refusal." Pacific Philosophical Quarterly, 92(3):415-437.

Neale, S., 1992. "Paul Grice and the philosophy of language." Linguistics and Philosophy, 15(5):509-559.

- - , 2005. "Pragmatism and binding." Z. G. Szabó (ed.), Semantics versus pragmatics, Clarendon, pp. 165-285.

---, 2016. "Silent reference." G. Ostertag (ed.), Meanings and other things: Themes from the work of Stephen Schiffer, OUP, pp. 229-344.

Open Science Collaboration, 2015. "Estimating the reproducibility of psychological science." Science, 349(6251). URL http://science.sciencemag.org/ content/349/6251/aac4716.

Quilty-Dunn, J. \& Mandelbaum, E., forthcoming. “Against Dispositionalism: Belief in Cognitive Science." Philosophical Studies, pp. 1-20.

Rosenthal, D. M., 1989. "Postscript to "Intentionality". Rerepresentations: Readings in the philosophy of mental representation, Kluwer Academic Publishers, pp. 341-344. Repr. in Rosenthal (2005), pp. 100-102.

,--- 2005 . Consciousness and mind. OUP.

Saul, J., 2006. "Gender and Race." Aristotelian Society Supplementary Volume, 80(1):119143.

Schiappa, E., 2003. Defining reality: Definitions and the politics of meaning. SIU Press. 
Schiffer, S., 1972. Meaning. OUP.

-- , 1992. "Belief ascription." The fournal of Philosophy, 89(10):499-521.

Scott, J. C., 1990. Domination and the arts of resistance: Hidden transcripts. Yale university press.

Searle, J., 1983. Intentionality: An essay in the philosophy of mind. CUP.

Sperber, D. \& Wilson, D., 1995. Relevance: Communication and cognition. Blackwell, 2 edn.

---, 2015. "Beyond speaker's meaning." Croatian fournal of Philosophy, 15(44):117149.

Strawson, P. F., 1964. "Intention and convention in speech acts." The Philosophical Review, 73(4):439-460. Repr. in Strawson (1971), pp. 149-169.

---, 1971. Logico-linguistic papers. Methuen.

Trivers, R., 2011. Deceit and self-deception: Fooling yourself the better to fool others. Penguin UK.

Unnsteinsson, E., 2017a. "A Gricean Theory of Malaprops." Mind and Language, 32(4):446-462.

-- , 2017b. "Saying without knowing what or how." Croatian Journal of Philosophy, 17(3):351-382.

---, 2018. "The Edenic Theory of Reference." Inquiry : An Interdisciplinary Journal of Philosophy, Online First:1-33. Doi: 10.1080/0020174X.2018.1446050.

West, C., 2003. "The Free Speech Argument Against Pornography." Canadian fournal of Philosophy, 33(3):391-422.

Wieland, N., 2007. "Linguistic Authority and Convention in a Speech Act Analysis of Pornography." Australasian fournal of Philosophy, 85(3):435-456.

Wilson, T. D., 2002. Strangers to Ourselves: Discovering the Adaptive Unconscious. Harvard University Press.

Young, I. M., 1990. "Five Faces of Oppression.” Justice and the Politics of Difference, Princeton University Press, pp. 39-65. 